\title{
ANALISIS KUALITAS PELAYANAN PERPUSTAKAAN SEKOLAH TINGGI TEKNOLOGI INDUSTRI (STTIND) PADANG DENGAN METODE QUALITY FUNCTION DEPLOYMENT (QFD)
}

\author{
Abdul Latif ${ }^{1}$, Purnomo Eka Nursyam ${ }^{2}$ \\ Teknik Industri, Sekolah Tinggi Teknologi Industri Padang \\ email: ${ }^{1}$ abdullatif@ sttind.ac.id, ${ }^{2}$ purnomoeka@gmail.com
}

\begin{abstract}
ABSTRAK
Layanan di perpustakaan STTIND Padang belum memenuhi keinginan mahasiswa yang berkepentingan untuk melakukan peminjaman buku, penyerahan buku ataupun kegiatan lainnya karena pada perpustakaan tidak ada karyawan yang bertugas secara tetap. Mahasiswa yang berkepentingan ke perpustakaan menjadi terhalang karena harus mencari karyawan yang bertugas di perpustakaan serta mahasiswa harus menunggu perpustakaan buka dengan waktu yang lama. Mahasiswa yang ingin membaca ataupun belajar menjadi malas karena tempat yang tidak strategis, ruangan perpustakaan yang sempit dan panas, buku yang tidak tersusun dengan rapi dan bersih, dan buku yang diinginkan pun tidak lengkap.Dalam analisis ini penulis membuat menggunakan metode Quantity Function Deployment (QFD). Tingkat kepuasan mahasiswa terhadap pelayanan yang diberikan perpustakaan STTIND Padang masih rendah didapat dari 16 atribut dengan nilai rata-rata yaitu 1,71. Diharapkan dengan adanya analisis ini, perpustakaan STTIND Padang dapat melihat atribut apa saja yang harus dikembangkan terlebih dahulu sesuai dengan derajat kepentingan dari tiap nilai atribut dan menjadikan perpustakaan menjadi lebih baik dari sebelumnya. Dari hasil penelitian ini upaya yang harus dilakukan untuk meningkatkan kualitas pelayanan perpustakaan STTIND Padang yakni meningkatkan kemampuan karyawan, meningkatakan jam kerja karyawan, meningkatkan keramaahan karyawan, penambahan bahan perpustakaan, pengecekan terhadap susunan bahan pustaka dirak, ruangan yang lapang, tenang, kualitas udara dan pencahayaan yang baik, layanan cleaning service, meningkatkan cara berpkaian karyawan dan membuat kartu anggota yang handal.
\end{abstract}

Kata kunci : Quantity Function Deployment (QFD), Perpustakaan

\section{PENDAHULUAN}

Saat ini, kebutuhan akan informasi adalah mutlak yang harus terpenuhi dalam kehidupan manusia. Pemanfaatan informasi tersebut tentunya sudah merambah ke seluruh bidang atau aspek kehidupan terutama di bidang pendidikan. Informasi yang diperlukan tidak hanya melalui internet saja, tetapi media cetak yang telah diterbitkan seperti buku, bukubuku tersebut dapat ditemukan di fakultas STTIND Padang. Perpustakaan STTIND Padang berdiri semenjak pertama kali kampus STTIND Padang didirikan yaitu tahun 1982. Namun kualitas pendidikan di
STTIND Padang tidak hanya dengan meningkatkan sumberdaya manusianya, akan tetapi harus diimbangi dengan tersedianya fasilitas pelayanan perpustakan yang memadai.

Layanan di perpustakaan STTIND Padang belum memenuhi keinginan mahasiswa yang berkepentingan untuk melakukan peminjaman buku, penyerahan buku ataupun kegiatan lainnya karena pada perpustakaan tidak ada karyawan yang bertugas tetap. Mahasiswa yang berkepentingan ke perpustakaan menjadi terhalang karena harus mencari karyawan yang bertugas di perpustakaan serta 
mahasiswa harus menunggu perpustakaan buka dengan waktu yang lama. Mahasiswa yang ingin membaca ataupun belajar menjadi malas karena tempat yang tidak strategis, ruangan perpustakaan yang sempit dan panas, buku yang tidak tersusun dengan rapi dan bersih, dan buku yang diinginkan pun tidak lengkap.

Layanan di perpustakaan dapat lebih memikat, bersahabat, cepat, dan akurat. Dengan adanya fasilitas perpustakaan yang memadai seperti buku yang lengkap, tersusun rapi, ruangan yang bersih, tempat yang strategis dan adanya AC sehingga mahasiswa akan semakin termotivasi untuk semangat belajar. Penulis akan menganalisa dengan menggunakan metode Quality Function Deployment (QFD).

Penelitian terhadap kualitas layanan perlu dilakukan dalam upaya meninggkatkan kualitas layanan dengan tujuan adanya peningkatan mutu pelayanan jangka panjang dan untuk mempertahankan kepuasan mahasiswa Fakultas Sekolah Tinggi Teknologi Industri (STTIND) Padang.

\section{METODOLOGI PENELITIAN}

\subsection{Jenis Penelitian}

Jenis penelitian yang digunakan dalam menganalisa tingkat kepuasan pelanggan atau pengunjung perpustakaan ini adalah deskripsi kuantitatif, dalam arti penelitian ini bersifat ilmiah yang sistematis terhadap bagian-bagian dan fenomena serta hubungan-hubungannya (Supriatman, 2010:41). Tujuan penelitian kuantitatif adalah mengembangkan dan menggunakan model-model matematis, teori-teori atau hipotesis yang berkaitan dengan fenomena alam. Proses pengukuran adalah bagian yang sentral dalam penelitian kuantitatif karena hal ini memeberikan hubungan yang fundemental antara pengamatan empiris dan ekspresi matematis dari hubungan-hubungan kuantitatif. Penulis menggunakan kuesioner untuk menghimpun data sesuai dengan variabel yang ada dalam teori-teori kepuasan dan loyalitas mahasiswa/mahasiswi.

\subsection{Tempat dan Waktu Penelitian}

Kegiatan penelitian dilakukan di Perpustakaan Sekolah Tinggi Teknologi Industri (STTIND) Padang. Penelitian dilaksanakan tanggal 5 Januari s/d 15 Februari 2017.

\subsection{Populasi dan Sampel}

Populasi adalah keseluruhan subjek penelitian (Arikunto, 2001:115). populasi merupakan langkah awal dalam penelitian yang bertujuan untuk mengetahui siapa yang menjadi responden. Dalam penelitian ini yang dijadikan objek penelitian adalah mahasiswa pengguna Perpustakaan Sekolah Tinggi seknologi (STTIND) Padang. Adapun jumlah mahasiswa pengguna Perpustakaan Sekolah Tinggi Tknologi (STTIND) Padang tahun 2015 adalah sebagai berikut:

Tabel 1 Jumlah Populasi

\begin{tabular}{|c|l|c|}
\hline No & \multicolumn{1}{|c|}{ Prodi } & $\begin{array}{c}\text { Jumlah Mahasiswa/Sis wi (STTIND) } \\
\text { Padang Tahun 2016 }\end{array}$ \\
\hline 1. & Teknik Industri & 200 \\
\hline 2. & Teknik Pertambangan & 757 \\
\hline 3. & Teknik Lingkungan & 110 \\
\hline 4. & Sistem Informasi & 105 \\
\hline & Jumlah & 1172 \\
\hline \multicolumn{3}{|c|}{ Penentuan } \\
\hline
\end{tabular}

penelitian ini dengan mengunakan teknik sampling kuota. Quota Sampling yang merupakan jumlah subjek yang akan diteliti ditetapkan lebih dahulu. Jika kuota telah ditentukan mulai penelitian dan tentang siapa yang akan dijadikan responden tersebut, kepada pengumpulan data. Untuk menentukan ukuran sampel dari suatu populasi dapat digunakan rumus Slovin (1960) yang dikutip sevilla (1994) sebagai berikut (Umar, 1997:49):

$$
\mathrm{n}=\frac{\mathrm{N}}{1+\mathrm{Ne}^{2}}
$$

dimana: $\mathrm{n}=$ Jumlah sampel

$$
\mathrm{e}=\text { Batas toleransi kesalahan }
$$




$$
\begin{gathered}
\mathrm{N}=\text { Jumlah populasi } \\
=\frac{1172}{1+1172 \cdot(0,1)^{2}}=\frac{1172}{1+11,72}=\frac{1172}{21,72} \\
=92,13=92
\end{gathered}
$$

Adapun jumlah rata-rata pengguna Perpustakaan Sekolah Tinggi Teknologi Industri (STTIND) Padang tahun 2015 adalah 1172 siswa maka dengan persentase kelonggaran $10 \%$ diperoleh jumlah respondennya sebanyak 92 responden.

\subsection{Variabel Penelitian}

Variabel penelitian merupakan pengelompokan yang logis dari dua atau lebih atribut (Singarimbun, 1989). Berdasarkan permasalahan yang diteliti, maka dalam penelitian ini terdapat yakni tingkat kepuasan pelanggan atau pengunjung Perpustakaan Sekolah Tinggi Teknologi Industri (STTIND) Padang.

\subsection{Data dan Sumber Data}

\section{Data Primer}

Data primer merupakan data yang diambil dari para responden yang menjadi jawaban atas kuisioner yang diberikan kepada responden, antara lain kepuasan kerja dan loyalitas karyawan. Data yang ada kemudian ditabulasikan dan dianalisa untuk pengujian statistik dalam penelitian ini.

\section{Data Sekunder}

Data sekunder adalah data yang diperoleh dari perusahaan yang menjadi gambaran umum kondisi perusahaan berupa wawancara.

\subsection{Teknik Pengolahan Data}

Teknik pengolahan data yang akan dilakukan adalah sebagai berikut :

A. Mengetahui tingkat kepuasan mahasiswa terhadap pelayanan yang diberikan perpustakaan STTIND Padang.

Langkah-langkah penelitian yang dilakukan yaitu :

1. Identifikasi populasi
2. Identifikasi sampel penelitian

3. Penyusunan kuesioner

4. Penyebaran kuesioner

5. Uji Validasi dan Reliabilitas

a. Uji Validasi

Uji validasi ini bertujuan untuk mengukur kualitas kuisioner yang dingunakan sebagai instrumen penelitian.

b. Uji Reabilitas

Untuk mengukur suatu kuesioner yang merupakan indikator dari variabel atau kontruksi. Microsoft Excel memberikan fasilitas untuk mengukur realibilitas dengan uji statistik Cronbach Alphan. Suatu konstruksi atau variabel dikatakan reliabel jika memberikan nilai Cronbach Alphan > 0,06 (Ghozali, 2001:42).

6. Pengolahan Data Quality Function Deployment (QFD)

Perhitungan QFD yang digunakan adalah analisis QFD yang artinya analisis matrik House Of Quality (HOQ) menggunakan lebih dari satu matrik

7. Matrik HOQ Customer Requitments To Technical Requirement Matrik HOQ level I :

a. Menentukan derajat kepentingan tiap atribut:

$$
\mathrm{x}=\frac{\sum_{\mathrm{i}-1}^{\mathrm{n}} \mathrm{DKi}}{\mathrm{n}}
$$

Dimana: Dki $=$ Derajat kepentingan responden ke-i

$$
\mathrm{n}=\text { Jumlah responden }
$$

b. Kinerja atribut jasa

$$
\mathrm{x}=\frac{\sum_{\mathrm{i}-1}^{\mathrm{n}} \mathrm{Ki}}{\mathrm{n}}
$$

Dimana: $\mathrm{Ki}=$ Kepuasan responden ke-i

$$
\mathrm{n}=\text { Jumlah responden }
$$

c. Menetukan nilai target dari setiap atribut jasa

d. Menetukan rasio perbaikan. 
e. Menentukan Sales poin

$$
\text { Rasio perbaikan }=\frac{\text { Nilai target }}{\text { Kinerja jasa }}
$$

f. Menetukan bobot dari setiap atribut jasa

Bobot $=$ Derajat Kepentingan $\times$ Rasio Perbaikan

g. Identifikasi parameter teknik (Technical Requirements)

h. Menentukan interaksi keinginan konsumen dengan parametr teknik.

1. Nilai matrik interaksi keinginan konsumen dengan parameter teknik.

$$
\begin{aligned}
& \mathrm{Kti}=\sum \mathrm{BTi} \times \mathrm{Hi} \\
& \mathrm{Kti}=\text { Nilai absolut parameter } \\
& \text { teknik setiap atribut } \\
& \mathrm{Bti}=\text { Kepentingan relatif (bobot) } \\
& \text { keinginana konsumen yang } \\
& \text { memiliki hubungan } \\
& \text { dengan atribut jasa } \\
& \mathrm{Hi}=\text { Nilai hubungan keinginan } \\
& \text { konsumen yang memiliki } \\
& \text { hubungan dengan atribut } \\
& \text { jasa. }
\end{aligned}
$$

2. Priritas parameter teknik berdasarkan kepentingan relatif

Kepentingan relatif =
$\frac{\text { Parameter Teknik Absolut }}{\sum \text { Parameter Teknik Absolut }} \times 100 \%$

\section{PENGOLAHAN DATA}

\subsection{Pengumpulan Data}

Pengumpulan data dalam penelitian ini dilakukan dengan metode survey. Data wawancara merupakan data awal yang ditampung dari beberapa mahasiswa yang berkaitan dengan keberadaan sebagai mahasiswa Sekolah Tinggi Teknologi Industri (STTIND) Padang. Data kuesioner berupa instrumen yang digunakan terdiri atas variabel kepuasan pengunjung Perpustakaan Sekolah Tinggi Teknologi Industri (STTIND) Padang.

Selain itu data yang diperoleh dengan cara melakukan pengamatan $\begin{array}{llll}\text { (observasi) } & \text { yaitu pencatatan } & \text { dan }\end{array}=\frac{40 .(16306)-(171) \times(3789)}{\left.\sqrt{\{40 \times 753}-(171)^{2}\right\} \times\left\{40 \times 362283-(3789)^{2}\right.}$ mendapatkan gambaran nyata dari masalah yang diamati pada

Data dari mahasiswa di peroleh melalui wawancara dan penyebaran kuesioner. Kuesioner ini diberikan kepada pengunjung Perpustakaan STTIND Padang untuk mengetahui atribut atau layanan apa saja yang diinginkan pengunjung. Penyebaran kuesioner kepada mahasiswa yang merupakan pengunjung Perpustakaan STTIND Padang untuk menentukan apa saja keinginannya terhadap perpustakaan tersebut.

\subsection{Pengolahan Data}

Uji Validitas

Uji validitas dalam penelitian ini menggunakan Microsoft Excel. Uji signifikasi dilakukan dengan membandingkan nilai $r$ hitung dengan $r$ tabel untuk degree of freedom $(\mathrm{df})=\mathrm{n}-2$, dalam hal ini $\mathrm{n}$ adalah jumlah sampel $(\mathrm{n})=$ $40,40-2=38$ dengan $\mathrm{df}=38$ dan alpha 0,05 didapat $r$ tabel $=0,3120$. Bandingkan hasil perhitungan $r$ hitung dengan $r$ tabel, jika $r$ hitung $>r$ tabel dan nilai positif maka butir atau pertanyaan tersebut dinyatakan valid. Hasil uji validitas dan realibilitas lebih jelas dapat dilihat pada lampiran. Perbandingan hasil uji validitas apabila data yang di peroleh $\mathrm{r}$ hitung $>$ dari $r$ tabel maka data tersebut dinyatakan valid yakni $r$ tabel didapat 0,3120 dan $r$ hitung keinginan pertama di dapat 0,3969 .

Rumus r hitung uji validitas :

$$
\frac{n \cdot\left(\sum x y\right)-\left(\sum x\right) \times\left(\sum y\right)}{\left.\sqrt{\left\{n \times \sum x^{2}\right.}-\left(\sum x\right)^{2}\right\} \times\left\{n \times \sum y^{2}-\left(\sum y\right)^{2}\right.}
$$

Salah satu contoh $r$ hitung uji validitas memperoleh pelayanan yang baik saat peminjaman buku adalah sebagai berikut: 


$$
\begin{array}{r}
=\frac{4321}{\sqrt{879.134799}}=\frac{4321}{\sqrt{118488321}} \\
=\frac{4321}{10885,23}=0,3969
\end{array}
$$

Berikut tabel hasil perhitungan secara keseluruhan :

Tabel 2 Hasil Uji Validitas Keinginan Mahasiswa

\begin{tabular}{|c|l|c|c|}
\hline $\mathrm{N}_{0}$ & \multicolumn{1}{|c|}{ Keinginan } & Nilai & Keterangan \\
\hline 1 & Memperoleh pelayanan yang baik saat peminjaman buku & 0,3969 & Valid \\
\hline 2 & Para petugas selalu menangagap permintann pengunjung & 0,4507 & Valid \\
\hline 3 & Mahasiswa tidak menunggu dalam antrian yang panjang & 0,4516 & Valid \\
\hline 4 & Perpustakaan selahu buka setiap hari & 0,5639 & Valid \\
\hline 5 & Prosedur pelayanan perpustakaan tidak berbelit-belit & 0,3999 & Valid \\
\hline 6 & $\begin{array}{l}\text { Cara petugas memperlakukan saya sesuai dengan yang } \\
\text { diharapkan }\end{array}$ & 0,3836 & Valid \\
\hline 7 & Perpustakaan menyediakan layanan waktu yang dijanjikan & 0,4848 & Valid \\
\hline 8 & $\begin{array}{l}\text { Petugas memiliki kemampuan untuk menjawab pertanyaan } \\
\text { mahasiswa }\end{array}$ & 0,4171 & Valid \\
\hline 9 & Petugas memahami kebutuhan mahasiswa yang spesifikasi & 0,4575 & Valid \\
\hline 10 & Petugas secara hati-hati mendengarkan permintaan mahasiswa & 0,624 & Valid \\
\hline 11 & $\begin{array}{l}\text { Petugas membantu mahasiswa dalam pencarian buku-buku } \\
\text { yang mahasiswa perlukan }\end{array}$ & 0,4767 & Valid \\
\hline 12 & $\begin{array}{l}\text { Fasiltas perpustakaan seperti loker, AC, komputer, ruangan } \\
\text { membaca tampak menarik dan bagus }\end{array}$ & 0,7782 & Valid \\
\hline 13 & Para petugas perpustakaan berpakaian rapi & 0,6849 & Valid \\
\hline 14 & Kebersihan dan kerapian perpustakaan terjaga & 0,8502 & Valid \\
\hline 15 & Buku-buku yang tersedia lengkap dan baik & 0,8004 & Valid \\
\hline 16 & Penempatan bahan pustaka di rak sesuai dengan lokasi & 0,763 & Valid \\
\hline
\end{tabular}

\section{Uji Reliabilitas}

Reliabilitas adalah indeks yang menunjukkan sejauh mana suatu alat pengukur dipercaya atau dapat diandalkan. Suatu kuesioner dapat dikatakan reliabel atau handal, jika jawaban responden terhadap pertanyaan adalah konsisten atau stabil dari waktu ke waktu. Dengan Microsoft Excel untuk mengukur reliabilitas dengan uji statistik Croanbach Alpha dengan nilai $>0,60$. Pada data kuesioner yang telah di uji didapat hasil dengan rumus :

$\mathrm{r}=\left[\frac{\mathrm{k}}{(\mathrm{k}-1)}\right]\left[1-\frac{\sum \sigma^{2}}{\sigma^{2}}\right]$

Keterangan : $\mathrm{r}=$ koefesien reliabilitas instrumen

(Cronbach Alpha)

$\mathrm{k}=$ banyaknya butir pertanyaan

$\sum \sigma 2=$ total varians butir

$\sigma^{2}=$ total varians

Hasil keseluruhannya yaitu

$r=\left[\frac{16}{(16-1)}\right]\left[1-\frac{12,58}{67,65}\right]$

$r=\left[\frac{16}{15}\right][1-0,19]$

$=(1,07)(0,81)=0,8667$

Jadi hasil akhir dari uji reliabilitas 0,8667 $>0,60 / 0,8667>$ dari pada $\mathrm{r}$ tabel $=$ 0,3120 jadi data kuesioner reliabilitas

\subsection{Pengolahan Data Quality Function Deployment (QFD)}

Perhitungan QFD yang digunakan adalah analisis QFD berantai, artinya analisis matrik House Of Quality (HOQ) menggunakan lebih dari satu matrik HOQ. Analisis QFD membolehkan lebih dari satu matrik HOQ dengan tujuan agar output dari QFD lebih teknis dan spesifik. Pada penelitian ini menggunakan dua matrik HOQ untuk hasil yang lebih optimal.

a. Derajat Kepentingan Relatif Butir

Keinginan Jasa

Derajat kepentingan digunakan untuk memposisikan setiap keinginan pengunjung dalam bentuk data kualitatif dengan tujuan untuk memproritaskan keinginan pengguna perpustakaan STTIND Padang. Pemberian bobot dimulai dari atribut yang sangat penting dengan nilai 5 sampai atribut yang sangat tidak penting dengan nilai 1 .

Derajat kepentingan yang diberikan oleh setiap responden dihitung tertera dengan rumus :

$$
\mathrm{x}=\frac{\sum_{\mathrm{i}=1}^{\mathrm{n}} \mathrm{DKI}}{\mathrm{n}}
$$

Salah satu contoh perhitungan derajat kepentingan relatif atribut sebagai berikut

$$
\begin{aligned}
\mathrm{x} & =\frac{\text { total pertanyaan ke } 1,2 \ldots \mathrm{n}}{\text { jumlah responden awal }} \\
\mathrm{x}=\frac{214}{92} & =2,326
\end{aligned}
$$


b. Nilai Target

Penetapan nilai target harus sesuai dengan kelebihan dan kelemahan perpustakaan dengan mempertimbangkan kondisi internal dan eksternal institusi.

\section{c. Rasio Perbaikan}

Rasio perbaikan bertujuan untuk mengetahui nilai yang harus dicapai oleh manajemen perpustakaan untuk mencapai nilai target yang ditetapkan. Bila nilai kinerja lebih besar atau sama dengan nilai target maka tidak perlu perbaikan. Rumus:

$$
=\frac{\text { Nilai Target }}{\text { Kinerja Jasa }}=\frac{5}{2,33}=2,15
$$

Tabel 3 Rasio Perbaikan

\begin{tabular}{|c|c|c|c|}
\hline Atribut & Target & $\begin{array}{c}\text { Kinerja } \\
\text { Jasa }\end{array}$ & $\begin{array}{c}\text { Rasio } \\
\text { Perbaikan }\end{array}$ \\
\hline 1 & 5 & 2,33 & 2,15 \\
\hline 2 & 4 & 2,10 & 1,91 \\
\hline 3 & 4 & 2,14 & 1,87 \\
\hline 4 & 5 & 0,80 & 6,22 \\
\hline 5 & 5 & 2,10 & 2,38 \\
\hline 6 & 5 & 2,12 & 2,36 \\
\hline 7 & 5 & 1,86 & 2,69 \\
\hline 8 & 4 & 1,99 & 2,01 \\
\hline 9 & 4 & 1,96 & 2,04 \\
\hline 10 & 4 & 1,74 & 2,30 \\
\hline 11 & 5 & 1,94 & 2,58 \\
\hline 12 & 5 & 1,33 & 3,77 \\
\hline 13 & 5 & 2,08 & 2,41 \\
\hline 14 & 5 & 0,85 & 5,90 \\
\hline 15 & 5 & 1,03 & 4,84 \\
\hline 16 & 5 & 1,02 & 4,89 \\
\hline
\end{tabular}

\section{d. Bobot Atribut Jasa}

Dengan mengetahui prioritas pengembangan atribut jasa, maka dapat ditentukan urutan atribut mana yang akan ditingkatkan dan dikembangkan. Bobot setiap atribut dapat dihitung dengan rumus :

Bobot $=$ Derajat Kepentingan $\mathrm{x}$ Rasio

Perbaikan

Salah satu contoh perhitungan tabel bobot atribut jasa sebagai berikut :

$$
\text { Bobot }=2,33 \times 2,15=5
$$

\section{e. Normalisasi Bobot Atribut Jasa}

Dari perhitungan bobot yang sudah diperoleh perlu dinormalisasikan. Menormalisasikan bobot bertujuan untuk memudahkan dalam menentukan prioritas pengembangan atribut mana yang perlu segera mendapat pengembangan. Normalisasi bobot dihitung dengan membagi bobot dengan total bobot.

\section{Normalisasi Bobot}

$$
\begin{aligned}
& =\frac{\text { Bobot }}{\text { Total Bobot }} \times 100 \% \\
& =\frac{5,00}{74,99} \times 100 \%=6,681
\end{aligned}
$$

\section{f. Parameter Teknik}

Parameter teknik merupakan hasil penterjemahan dari keinginan konsumen, dari keinginan konsumen diterjemahkan ke dalam bahasa teknik yang dapat diukur untuk menentukan target yang akan dicapai dan untuk menentukan atribut mana yang nantinya akan dikembangkan.

Untuk menentukan parameter mana yang harus dinaikkan atau diturunkan, tentunya kita harus wawancara dengan responden, untuk mengetahui parameter teknik yang sesuai dengan keinginan konsumen.

g. Interaksi Antara Keinginan Konsumen dengan Parameter Teknik

Tahap ini dimaksudkan untuk mengetahui keeratan hubungan masingmasing komponen parameter teknik dalam memenuhi keinginan konsumen. Tiga tipe hubungan yang digunakan adalah:

()) = Tingkat hubungan kuat dengan nilai 9

$O=$ Tingkat hubungan sedang dengan nilai 3

$\bigwedge=$ Tingkat hubungan lemah dengan nilai 1 
h. Nilai Matrik Interaksi Keinginan Konsumen Dengan Parameter Teknik

Matrik interaksi adalah untuk menghubungkan antara atribut jasa yang dianggap penting oleh konsumen dengan parameter teknik yang telah disusun. Lemah dan kuatnya interaksi yang terjadi dipengaruhi oleh tingkat kedekatan antara atribut jasa dengan parameter teknik. Interaksi yang terjadi kemudian dinyatakan dalam angka dan simbol. Interaksi ini harus dikalikan dengan normalisasi bobot dari setiap atribut yang telah dihitung sebelumnya, sehingga menghasilkan nilai untuk setiap parameter teknik dan atribut jasa. Nilai ini kemudian dijumlahkan sehingga diketahui total setiap parameter teknik. Setelah diketahui nilai setiap parameter teknik, maka dapat menentukan parameter teknik mana yang menjadi prioritas untuk dikembangkan terlebih dahulu.

$$
K T i=\sum B T i x H i
$$

Keterangan :

$\mathrm{KTi}=$ Nilai absolut parameter teknik untuk masing-masing atribut.

$\mathrm{BTi}=$ Kepentingan relatif (bobot atau normalisasi bobot) atribut jasa yang diinginkan yang memiliki hubungan dengan atribut parameter teknik.

$\mathrm{Hi}=$ Nilai hubungan atau interaksi antara atribut jasa yang diinginkan dengan parameter teknik.

Salah satu contoh perhitungan tabel nilai interaksi parameter teknik sebagai berikut:

$$
\begin{aligned}
& \text { KTi }=(9 \times 6,681)+(9 \times 5,347) \\
& \quad+(9 \times 6,668) \\
& =60,129+48,123+60,012=168,264
\end{aligned}
$$

jadi 168,3

\begin{tabular}{|c|c|c|}
\hline No & Parameter Teknik & Nilai \\
\hline 1 & $\begin{array}{l}\text { Meningkatkan } \\
\text { keramahan karyawan }\end{array}$ & 168,3 \\
\hline 2 & $\begin{array}{l}\text { Meningkatkan } \\
\text { kemampuan karyawan }\end{array}$ & 455,9 \\
\hline 3 & $\begin{array}{l}\text { Meningkatkan jam } \\
\text { kerja karyawan }\end{array}$ & 233,3 \\
\hline 4 & $\begin{array}{l}\text { Membuat kartu } \\
\text { anggota yang handal }\end{array}$ & 20,0 \\
\hline 5 & $\begin{array}{l}\text { Ruang yang lapang, } \\
\text { tenang, kualitas udara } \\
\text { dan pencahayaan yang } \\
\text { baik }\end{array}$ & 119,9 \\
\hline 6 & $\begin{array}{l}\text { Meningkatkan cara } \\
\text { berpakaian karyawan }\end{array}$ & 60,0 \\
\hline 7 & $\begin{array}{lr}\text { Pelayanan } & \text { cleaning } \\
\text { service } & \text { seluruh } \\
\text { ruangan perpustakaan }\end{array}$ & 119,9 \\
\hline 8 & $\begin{array}{lr}\begin{array}{l}\text { Penambahan } \\
\text { pustaka }\end{array} & \text { bahan } \\
\text { perpustakaan) } & \\
\end{array}$ & 167,9 \\
\hline 9 & $\begin{array}{l}\text { Pengecekan terhadap } \\
\text { susunan bahan pustaka } \\
\text { di rak oleh karyawan }\end{array}$ & 120,0 \\
\hline Jumlah & 1465,2 & \\
\hline
\end{tabular}

Hasil perhitungan selengkapnya dapat dilihat sebagai berikut :
Tabel 4 Nilai Interaksi Parameter Teknik

Sedangkan perhitungan tingkat kepentingan relatif dari parameter teknik diperoleh dari hasil bagi antara masingmasing parameter teknik absolut dengan jumlah total dari parameter teknik absolut dikalikan $100 \%$.

$$
\text { Kepentingan Relatif }=\frac{\mathrm{KTi}}{\sum \mathrm{KT}} \times 100
$$

Contoh sebagai berikut :

Kepentingan Relatif

$$
\begin{aligned}
& =\frac{\text { Parameter Teknik }}{\text { Total Parameter }} \times 100 \\
=\frac{168,3}{1465,2} \times 100 & =11,48
\end{aligned}
$$


Hasil keseluruhan dari perhitungan nilai matrik sebagai berikut :

Tabel 5vNilai Matrik Interaksi Parameter Teknik (dalam \%)

\begin{tabular}{|c|l|c|}
\hline No & \multicolumn{1}{|c|}{ Parameter Teknik } & Nilai (\%) \\
\hline 1 & $\begin{array}{l}\text { Meningkatkan } \\
\text { keramahan karyawan }\end{array}$ & 11,48 \\
\hline 2 & $\begin{array}{l}\text { Meningkatkan } \\
\text { kemampuan karyawan }\end{array}$ & 31,12 \\
\hline 3 & $\begin{array}{l}\text { Meningkatkan jam } \\
\text { kerja karyawan kartu }\end{array}$ & 15,92 \\
\hline 4 & $\begin{array}{l}\text { Membuat lapang, } \\
\text { anggota yang handal }\end{array}$ & 1,36 \\
\hline 5 & $\begin{array}{l}\text { Ruang yang lapang } \\
\text { tenang, kualitas udara } \\
\text { dan pencahayaan yang } \\
\text { baik }\end{array}$ & $\begin{array}{l}\text { Meningkatkan cara } \\
\text { berpakaian karyawan }\end{array}$ \\
\hline 7 & $\begin{array}{l}\text { Pelayanan cleaning } \\
\text { service seluruh ruangan } \\
\text { perpustakaan }\end{array}$ \\
\hline 8 & $\begin{array}{l}\text { Penambahan bahan } \\
\text { pustaka } \\
\text { perpustakaan) }\end{array}$ \\
\hline 9 & $\begin{array}{l}\text { Pengecekan terhadap } \\
\text { susunan bahan pustaka } \\
\text { di rak oleh karyawan }\end{array}$ \\
\hline Jumlah & 8,10 \\
\hline $\begin{array}{l}\text { Adapun prioritas parameter } \\
\text { berdasarkan kepentingan relatif }(\%) \text { dapat } \\
\text { dilihat pada tabel berikut: }\end{array}$ \\
\hline
\end{tabular}

Tabel 6 Prioritas Parameter Teknik

\begin{tabular}{|c|l|c|c|}
\hline No & \multicolumn{1}{|c|}{$\begin{array}{c}\text { Parameter } \\
\text { Teknik }\end{array}$} & $\begin{array}{c}\text { Nilai } \\
(\%)\end{array}$ & Prioritas \\
\hline 1 & $\begin{array}{l}\text { Meningkatkan } \\
\text { keramahan } \\
\text { karyawan }\end{array}$ & 11,48 & 3 \\
\hline 2 & $\begin{array}{l}\text { Meningkatkan } \\
\text { kemampuan } \\
\text { karyawan }\end{array}$ & 31,12 & 1 \\
\hline
\end{tabular}

\begin{tabular}{|c|c|c|c|}
\hline 3 & $\begin{array}{l}\text { Meningkatkan } \\
\text { jam kerja } \\
\text { karyawan }\end{array}$ & 15,92 & 2 \\
\hline 4 & $\begin{array}{ll}\text { Membuat } & \text { kartu } \\
\text { anggota } & \text { yang } \\
\text { handal } & \\
\end{array}$ & 1,36 & 9 \\
\hline 5 & $\begin{array}{l}\text { Ruang yang } \\
\text { lapang, tenang, } \\
\text { kualitas udara } \\
\text { dan } \\
\text { pencahayaan } \\
\text { yang baik }\end{array}$ & 8,18 & 6 \\
\hline 6 & $\begin{array}{l}\text { Meningkatkan } \\
\text { cara berpakaian } \\
\text { karyawan }\end{array}$ & 4,10 & 8 \\
\hline 7 & $\begin{array}{l}\text { Pelayanan } \\
\text { cleaning service } \\
\text { seluruh ruangan } \\
\text { perpustakaan }\end{array}$ & 8,18 & 7 \\
\hline 8 & $\begin{array}{l}\text { Penambahan } \\
\text { bahan pustaka } \\
\text { (koleksi } \\
\text { perpustakaan) }\end{array}$ & 11,46 & 4 \\
\hline 9 & $\begin{array}{l}\text { Pengecekan } \\
\text { terhadap } \\
\text { susunan bahan } \\
\text { pustaka di rak } \\
\text { oleh karyawan }\end{array}$ & 8,19 & 5 \\
\hline
\end{tabular}

i. Hubungan Antara Parameter Teknik

Pengidentifikasian hubungan antar parameter teknik perlu dilakukan guna mengetahui adanya pertukaran antara masing-masing atribut pada parameter teknik tersebut adalah:

1. Hubungan positif kuat yaitu apabila dua atribut tersebut masing-masing saling mendukung dalam pelaksanaannya dan sifat hubungan sangat kuat.

2. Hubungan positif moderat yaitu apabila dua masing-masing saling mendukung dalam pelaksanaannya dan sifat hubungan sedang. 
3. Tidak ada hubungan yaitu bila dua atribut masing-masing tidak terdapat hubungan apapun. Penentuan prioritas terhadap parameter teknik apa yang akan dikembangkan perlu mempertimbangkan interaksi diantara parameter teknik. Interaksi antara parameter teknik dapat dilihat pada tabel berikut :

\section{Tabel}

Interaksi Antar Parameter

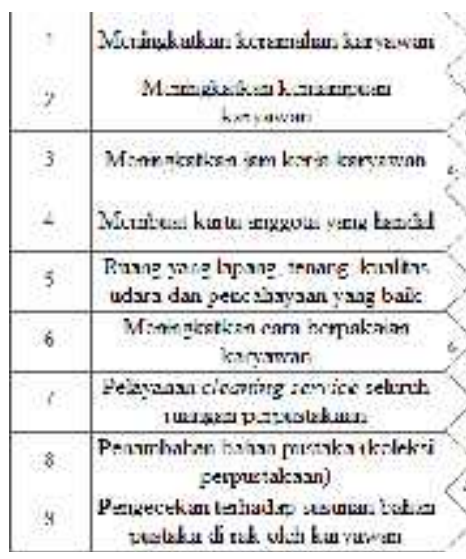

\section{j. Matrik HOQ Customer Requirement to Tehnical Requierement}

Matrik House Of Quality ini menjelaskan apa saja yang menjadi keinginan konsumen dan bagaimana memenuhinya. Matrik ini dibuat berdasarkan penggabungan pengolahan data dari penentuan derajat kepentingan sampai dengan interaksi parameter teknik, dan hasil dari matrik ini sudah dapat diterapkan pada operasional institus. Hasilnya sebagai berikut :

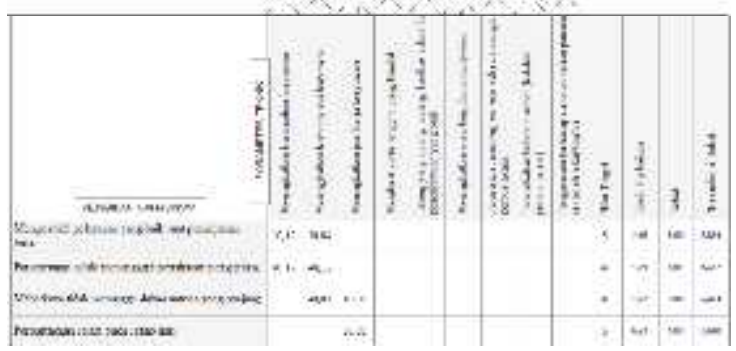

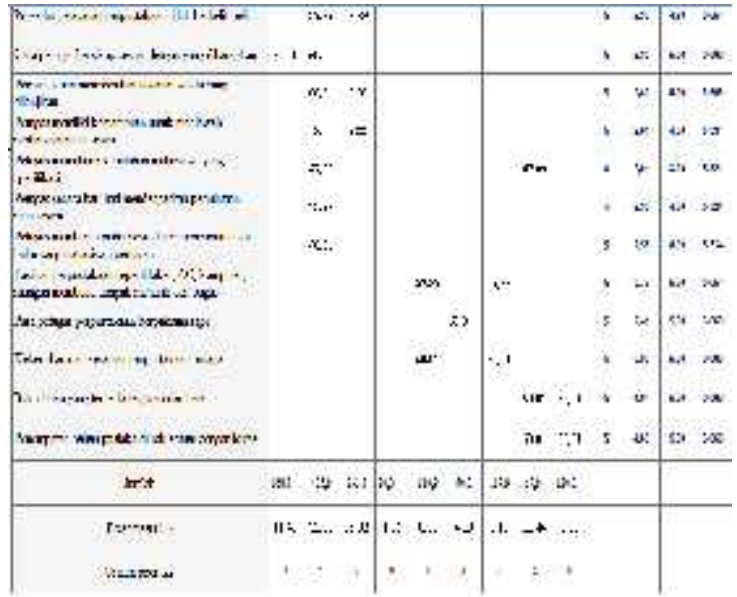

\section{KESIMPULAN DAN SARAN}

\subsection{Kesimpulan}

Dari tujuan penelitian dan pengolahan data maka didapat kesimpulan yaitu sebagai berikut :

1. Tingkat kepuasan mahasiswa terhadap pelayanan yang diberikan perpustakaan STTIND Padang masih rendah yaitu didapat dari 16 atribut yang mana dari 16 atribut yang diperoleh hasil derajat kepentingan yaitu 1,71 .

2. Upaya yang harus direkomendasikan untuk meningkatkan kualitas layanan adalah dari tabel prioritas yaitu :

a. Meningkatkan kemampuan karyawan yaitu dengan nilai interaksi parameter teknik.

b. Meningkatkan jam kerja karyawan.

c. Meningkatkan keramahan karyawan.

d. Penambahan bahan pustaka (koleksi perpustakaan).

e. Pengecekan terhadap bahan pustaka di rak oleh karyawan.

f. Ruang yang lapang, tenang, kualitas udara dan pencahayaan yang baik.

g. Pelayanan cleaning service seluruh ruangan perpustakaan.

h. Meningkatkan cara berpakaian karyawan.

i. Membuat kartu anggota yang handal. 


\subsection{Saran}

Dari penelitian yang telah dilakukan, penulis memberikan beberapa saran yaitu :

1. Kepada pihak manajemen perpustakaan STTIND Padang untuk dapat melakukan pengembangan pelayanan di perpustakaan dengan memperhatikan urutan prioritas yang berdasarkan hasil pengolahan dan analisis Quality Function Deployment (QFD) agar sesuai dengan harapan atau keinginan mahasiswa.

2. Peningkatan pelayanan perpustakaan perlu dilakukan agar kampus STTIND menjadi lebih baik lagi.

\section{DAFTAR PUSTAKA}

Arikunto, Suharsini, Prosedur Penelitian Suatu Pendekatan Praktek, Rineka Cipta, Jakarta, 2001.

Arini, Wahyu, Manajemen Kualitas, Ghalia Indonesia, Jakarta, 2003.

Cohen, L, Quality Function Deployment, How To Make QFD Work For You.Singapore, AddisonWesleypublishing Company, 1995.

Fajrin, Fibrinda, Analisis Kualitas Pelayanan Jasa Di Perpustakaan Pusat Universitas Muhammadiyah Surakarta Menggunakan Metode Serqual Gap. Surakarta, Teknik Industri UMS, 2006.

Gaspersz, Vincent,Total Quality Managemen, PT. Gramedia Pustaka Utama, Jakarta, 2001.

Groover, Mikell P, Automation, Production System, and ComputerIntegrated Manufacturing, Edisi Kedua, Prentice-Hall International, New Jersey, 2005.
Ghozali, Imam, Aplikasi Analisis Multivariate Dengan Program SPSS, Badan Penerit Universitas Diponegoro, 2001.

H. S. Lasa, Manajemen Perpustakaan, Gama Media, Yogyakarta, 2005.

Kotler, Philip, Manajemen Pemasaran Analisis Perencanaan, Implementasidan Kontrol, $\quad P T$. Prenhallindo, Jakarta, 1998.

Margono, Metodologi Penelitian Pendidikan, Rikena Cipta, Jakarta, 2004.

Nasution, M.N, Manajemen Mutu Terpadu (Total Quality Management), Ghalia Indonesia, Jakarta, 2001.

Qalyubi, Syihabuddin dkk, Dasar-Dasar Ilmu Perpustakaan dan Informa, UIN Sunan Kalijaga, Yogyakarta, 2007.

Ratiminto dan Atik Winarsih, Manajemen Pelayanan, Pustaka Pelajar, Yogyakarta, 2005.

Supranto, Pengukuran Tingkat Kepuasan Pelanggan, Cetakan Ketiga, Rineka Cipta, Jakarta, 2006

Sutarno, Perpustakaan dan Masyarakat, IKAPI, Jakarta, 2006.

Supranto. J, Pengukuran Tingkat Kepuasan Pelanggan Untuk Menaikkan Pangsa Pasar, Rineka Cipta, Jakarta, 1997.

Sugiyono, Perilaku Pembelian Komsumen dan Komunikasi Pemasaran, Rosda, Bandung, 2001.

Soeasminah, Perpustakaan Kepustakaan dan Pustakawan, Gama Media Yogyakarta, 1998. 
Supriatman, Dadan, Analisis Dari Buku Metodologi Penelitian, Yayasan Muhamad Yamin Sekolah Tinggi Teknologi Industri (STTIND), Padang, 2010.

Susanto, Afi, Analisis Kualitas Pelayanan Pelanggan Dengan Metode Quality Function Deployment (QFD), Surakarta, Teknik Industri UMS, 2006.

Sugiarto, Teknik Sampling, PT,Gramedia Pustaka Utama, Jakarta, 2001.

Tjiptono, Fandy dan Diana, Anatasia, Total Quality Management, Andi Offset.Jakarta, 1995.

Tjiptono, Fandy dan Diana, Anatasia, Total Quality Management, Andi Offset.Jakarta, 2012.

Tjiptono, Fandy, Strategi Pemasaran, Andi Offset, Yogyakarta, 2001.

Tjiptono, Fandy, Strategi Pemasaran, Edisi 2, Andi Offset, Yogyakarta, 2004.

Umar, Husein, Metodologi Penelitian Aplikasi dalam Pemasaran, PT.Gramedia Pustaka Utama, Jakarta, 1997.

Wahyu, Arini, Manajemen Kualitas, Universitas Atmajaya, Yogyakarta, 1999.

Yamit, Zulian, Manajemen Kualitas Produk dan Jasa, Yogyakarta, Ekonesia, 2002. 